\title{
Uniões de Pessoas do Mesmo Sexo - reflexões éticas e jurídicas ${ }^{1}$
}

\author{
Rodriga da Cunha Pereirat
}

Advogado, Professor de Direito de Familia da PUC/MG, Mestre em Direito Civil-UFMG.

\section{SUMÁRIO}

1. Sexo legítimo e ilegítimo;

2. Avesso do Avesso; O gozo é perverso;

3. Inclusão e exclusão no laço social e jurídico; Alteridade;

4. Variantes ou desviantes da sexualidade humana?

5. Consequências jurídicas das relações de afeto: o projeto Marta Suplicy e os fantasmas da sexualidade; civil;

5.1. O conteúdo do projeto de parceria

6. Concluindo: Ética do Direito;

Bibliografia.

\section{Sexo legítimo e ilegítimo}

Sexo, casamento e reprodução. Premissas e elementos básicos em que sempre esteve apoiado o DIREITO DE FAMÍLIA, sustentados nos ordenamentos jurídicos ocidentais, pelo princípio da monogamia. Com a evolução do conhecimento e a mudança dos costumes, especialmente a partir da década de 60 , estes elementos básicos desatrelaram-se um do outro. Hoje é possível reproduçấo sem sexo, sexo sem casamento e também tem sido comum, casamento sem reprodução. Vê-se, portanto, que os paradigmas e princípios estruturadores do Direito de Família ficaram alterados. A Constituição de 1988 modificou profundamente a organização jurídica da família brasileira, quando reconhece em seu art. 226 outras formas de família, além daquela constituída pelo casamento. Portanto, o casamento não é mais a única forma de legitimação de famílias. Há também aquelas constituídas pela

1. Palestra proferida no "Congresso Brasileiro de Direito Privado", em 02/10/97 - Olinda-PE). 
união estável (concubinato não-adulterino) e as famílias monoparentais (qualquer dos pais que viva com seus descendentes). Isto significa, em outras palavras, que o Estado reconhece que as relações sexuais legítimas (permitidas), não são mais, somente, aquelas praticadas dentro do casamento.

O Direito de Família é a tentativa de regulamentação e organização de relações que são da ordem da sexualidade. Portanto, quando falamos de Direito de Família, estamos falando de sexualidade. Aliás, a primeira Lei, é uma Lei de Direito de Família, que é uma proibição sexual: o interdito proibitório do incesto. Essa interdição, segundo Levi STRAUSS ${ }^{2}$ e FREUD 3 é a Lei fundante do sujeito e possibilitadora das organizações sociais e, conseqüentemente, jurídicas, pois é a partir deste interdito que é possível a passagem da natureza para a cultura. Em outras palavras: se a lei básica da família tem sua origem em uma proibição sexual, conseqüentemente, toda a organizaçăo jurídica sobre ela gira em torno da sexualidade.

Mesmo com a alteração dos princípios e paradigmas do Direito de Família, continuamos identificando socialmente as pessoas por suas preferências ou inclinações sexuais. De alguma forma estamos sempre procurando colocar o selo da legitimidade ou ilegitimidade em determinadas relações sexuais. É instigante observamos também como nos interessamos tanto pela sexualidade alheia, a ponto de classificá-la conde- nável, ou não, para os princípios morais e sociais. Jurandir Freire, psicanalista carioca é quem nos traz esta reflexão:

Quando e de que maneira poderemos ensinar, convencer, persuadir as novas gerações de que classificar sociomoralmente pessoas por suas inclinações sexuais é uma estupidez que teve, historicamente, péssimas conseqüências éticas. Muitos sofreram por isto; muitos mataram e morreram por esta crença inconseqüente e humanamente pernicio$\mathrm{sa}^{4}$

Das preferências sexuais mais estig. matizadas está aquela em que se faz a escotha pelo mesmo sexo. Indaga-se ainda hoje, se a homossexualidade é orgânica ou psicológica, se é um desvio, uma doença ou uma perversão. $\mathrm{O}$ Conselho Federal de Me. dicina-CRM, antecipando-se à Organização Mundial de Saúde-OMS, em 1985, tornou sem efeito o código 302 da Classificação Internacional de Doenças (CID), não mais considerarido a homossexualidade como desvio ou transtorno sexual.

Na verdade, essa exaustiva discussão nunca chegou a lugar algum e tem servido apenas para conduzi-la ao campo da moral e da estigmatização.

\section{Avesso do Avesso; 0 gozo é perverso}

O Direito é um dos mais importan. tes instrumentos de inclusão e exclusão das pessoas no laço social. É o Estado, através

2. STRAUSS, Claude Levi. Estruturas elementares do parentesco. Trad. Mariano Ferreira. Petrópolis: Vozes, 1982. p. 62.

3. FREUD, Sigmund. Totem e Tabu. In: Obras Psicológicas Completas. Trad. Orizon Carneiro. Rio de Janeiro: Imago, 1974. v. XII, p. 36 .

4. FREIRE, Jurandir. Entrevista. Jornal do Psicólogo, Belo Horizonte, n. 51, p. 3, 1995. 
de seu ordenamento jurídico, quem prescreve as normas de apropriação ou expropriação à categoria de cidadãos. A História já nos demonstrou que esses critérios de inclusão e exclusão trazem consigo um traço ideológico que não pode mais ser desconsiderado pelo Direito, sob pena de se continuar repetindo injustiças e reproduzindo ainda muito sofrimento. Basta lembrarmos, por exemplo, que a mulher no Brasil, só foi considerada cidadã pela Constituição de 1934, e adquiriu capacidade jurídica somente em 1962, pela Lei 4.121 (Estatuto da Mulher Casada). Foucault, em seu livro História da Loucura, já nos revelou há muito tempo o traço perverso da ideologia dos excluídos, quando, por exemplo, eram encarcerados os heréticos, os leprosos, os feiticeiros, etc.

Um dos principais critérios de expropriação da cidadania sempre foi o de desconsiderar o diferente. Em outras palavras, aquilo que não conheço, não domino, ou não faz parte do meu universo, é mais cômodo ignorar ou repelir, pois assim não estarei ameaçadio. Caetano v̌eiosu, aliás, já disse isso de maneira magistral em sua composição "Sampa": frente

Quando eu te encarei frente a

Não vi o meu rosto

Chamei de mau gosto

O que vi de mau gosto, mau gos-

to

É que narciso acha feio

O que não é espelho

(...)

Afasto o que não conheço
E quem vem de outro sonho feliz de cidade

(...)

Porque é o avesso do avesso

Do avesso do avesso ${ }^{5}$

Ainda temos visto a serviço do Estado, nesta exclusão do laço social, a identificação sociomoral das pessoas por suas preferências sexuais. A tendência é mesmo de estigmatização e marginalização de todos aqueies que não têm suas preferências sexuais de acordo com determinados padrões de normalidade. Insistimos todos na busca de uma normalidade sexual, como se existisse neste campo, o normal e o anormal. Afinal, o que é normal em termos de relaçāo sexual? Sāo as formas convencionais? Mas, o que sāo essas formas convencionais? Quais são as formas do prazer sexual? Cada um constrói a sua forma (fantasia) de acordo com a sua particularidade, que advém de sua história pessoal e que o constituiu sujeito. E o ser enquanto sujeito, é um sujeito desejante. E o que é o desejo? Segundo Jacques LACAN, desejo é desejo de desejo. E o desejo, psicanaliticamente falando, é sempre da ordem do INCONSCIENTE. Ora, sexualidade é da ordem do Desejo e desenvolve-se inteiramente na ordem da fantasia. Será que poderíamos, enfim, dizer que em termos de sexualidade existe o normal e o anormal? Para LACAN, o prazer sexual, ou o gozo sexual, é sempre da ordem da perversão, já que escapa ao normal ou normatizável. É que o ato de gozar só se torna possível se sairmos da racionalidade, do normatizável.

5. O Melhor de Caetano Veloso - Sem lenço sem documento. Local: Polygram, 1989. 1 CD. 


\section{Inclusão e exclusão do laço social e jurídico; Alteridade}

As constituiçōes democráticas do fim deste século, em conseqüência das idéias iluministas do final do século passado, vêm expressando a palavra de ordem da contemporaneidade: cidadania. "Todos são iguais perante a lei, sem distinção de qualquer natureza" (art. 5, CF). Assim, todos estão incluídos no laço social e poderão participar do processo histórico evolutivo e da organização da polis. $\mathrm{O}$ princípio da igualdade como inclusão no laço social é um avanço, mas não basta. É que a igualdade proclamada de forma genérica, como anunciada nos textos constitucionais, na medida em que vai se generalizando, vai se tornando cada vez mais abstrata. $\mathrm{Na}$ medida em que vai se tornando abstrata, pode ter efeito contrário, ou seja, vai se distanciando da igualdade de direitos. Talvez devêssemos, antes de tudo, considerar as diferenças. É a partir das diferenças e da convivêricia com a alteridade que se faz a verdadeira democracia e torna-se possível estar mais próximo do ideal de justiça.

A partir, portanto, do ideal democrático, e da inclusão no laço social é que alguns países vêm tentando possibilitar a inclusão de alguns considerados historicamente diferentes. Diferentes ou não, a reivindicação é sempre de um "lugar ao sol" e de uma desmarginalização.

Caio Mário da Silva Pereira, em recente trabalho publicado sobre o assunto, registra que o aumento do homossexualismo e os casos de homossexuais que vivem juntos, como se fossem casais, têm feito com que alguns sistemas jurídicos reformulem suas leis para acomodar tais situações. Com isto e a evolução dos costumes,

OParlamento Europeu pediu que os países da União Européia permitam o casamento de homossexuais. Em harmonia com essa recomendação, exortou os países da União Européia a abolirem a discriminação de homossexuais e deixarem de penalizá-los. Condenou em particular a Grã-Bretanha que, a pretexto de evitar o homossexualismo, vem promovendo restriçōes aos direitos dos cidadãos em várias áreas. Neste sentido, o Parlamento Britânico amenizou as limitações, reduzindo a idade consentida para relações homossexuais de 21 anos para 18 anos. $^{6}$

Alguns ordenamentos jurídicos como o da Noruega, Hungria, Suécia, Holanda, Estado de Nova Iorque (EUA), por exem. plo, já estabeleceram normas de convivência para as uniões do mesmo sexo. Em 1989, o parlamento dinamarquês, seguindo uma tendência dos países nórdicos, aprovou um projeto de lei autorizando o registro de uniões homossexuais, com os mesmos efeitos legais do casamento, exceto em relação à adoção de crianças. ${ }^{7}$ Paradoxalmente, o país onde menos se soube conviver com as diferenças, África do Sul, é o que tem a primeira constituição do mundo (1996) onde está expressamente proibida a discriminação em razão da opção sexual.

6. PEREIRA, Caio Mário da Silva. Revista do Instituto dos Advogados de Minas Gerais, Belo Horizonte, n. 1, p. 275, 1995. 7. VINDELOV, Vibeke. Family Law in Denmark. In: Family, law and social policy - OÑATI. Valério Pocar and Paola Ronfani, 1991. p.
176. 
No Brasil, a lei não toma conhecimento do homossexualismo, não lhe dá aprovaçōes nem punições. Mas, como na maioria dos Estados ocidentais, a doutrina admite casamento somente entre pessoas de sexos opostos, ou seja, heterossexual. Aqueles realizados entre pessoas do mesmo sexo são considerados pela doutrina como casamento inexistente. Decisão histórica no Brasil sobre o assunto foi o rumoroso caso de dissolução de relação homossexual, com conseqüente partilha de bens, em que o Tribunal, apesar de determinar tai procedimento, negava qualquer possibilidade desse tipo de uniăo. In verbis, ementa do acórdão unânime da $5^{\text {a }}$ Câmara Cível do TJRJ, n. 47.965, rel. Des. Narciso Pinto:

Comprovada a conjugação de esforços para a formação do patrimônio que se quer partilhar, reconhece-se a existência de uma sociedade de fato e determina-se a partilha [...]. Deve-se observar, desde logo, que nenhuma importância tem, para apreciação do pedido, a natureza das relações que ligaram o autor à nessoa de Jorge Guinle, não cabendo aqui qualquer discussão sobre se, entre eles existiu este ou aquele tipo de relacionamento, apresentando-se pois, inteiramente despropositadas as considerações feitas pelo réu, ora apelante, a respeito de possíveis ligaçōes amorosas ou sexuais entre o autor o finado Jorge.

Começa a tornar-se menos incomum nos tribunais brasileiros, os casos envolvendo parceiros do mesmo sexo. Por exemplo, em 10.6.96, a 9ª Vara Cível da Comarca de Belo Horizonte, julgou procedente o pedido de um companheiro, que reivindicou, dentre outras coisas, partilha dos bens adquiridos na constância da união:
Julgo em parte procedente o pedido para conferir ao autor o direito à metade do imóvel.... com inserção do seu nome no Registro imobiliário... além do direito ao ressarcimento de $50 \%$ dos gastos feitos com a manutenção das sociedades comerciais(...).

O Tribunal de Alçada de Minas Gerais reformou a sentença de primeira instância, e neste momento, o caso aguarda decisão do STJ.

\section{Variantes ou desviantes da sexualidade humana?}

É preciso diferenciar aqui as relaçōes homossexuais, isto é, dois homens ou duas mulheres que estabelecem um relação amorosa-sexual, daquelas a que se denomina transexualismo. Nesses casos, e que não são objeto deste trabalho, são pessoas que têm interesse em mudar de sexo através de uma cirurgia. Para o Direito, interessa saber se uma pessoa, tendo mudado de sexo, estaria simplesmente transfigurando sua sexualidade, ou se røalmente adquirirá a identidade do sexo oposto. No Brasii, nào há nenhuma legislação sobre o assunto. $\mathrm{Na}$ doutrina, uma corrente entende que a operação para mudança de sexo é impossível, e juridicamente constitui lesão corporal, crime tipificado no Código Penal. No Direito Estrangeiro, não se tem notícia de regulamentação nesse sentido. Mas a imprensa registrou, no ano de 1995, que um decreto islâmico egípicio passou a autorizar a troca de sexo:

Um homem pode submeter-se a uma cirurgia para tornar-se mulher, e uma mulher pode fazer a operaçăo inversa, se um médico de confiança com- 
provar que a intervenção é necessária para afirmar a feminilidade ou virilidade existentes, mas ocultas. ${ }^{8}$

A mesma agência de notícias informou que a prefeita eleita de uma cidade da Nova Zelândia era um homem transformado em mulher através de cirurgia. Mas esses casos săo apenas para ilustrar que a sexualidade humana, intrincada e comple$\mathrm{xa}$, pode ter muitas variáveis. Interessa-nos, aqui, pensar a homossexualidade e suas implicações no Direito, e no contexto deste trabalho, se seria uma outra possibilidade de união estável.

\section{Conseqüências jurídicas das relações de afeto: o projeto Marta Suplicy e os fantasmas da sexualidade}

Tramita no Congresso Nacional o Projeto de Lei n. 1.151, de 1995, de autoria da Deputada Marta Suplicy, que disciplina as uniões homossexuais. Afora suas imprecisões técnicas e toda a polêmica que ele tem levantado, aprovaúo cui iã̃o, é indicativo da reivindicação do reconhecimento pelo Estado da existência dessas relações. É significativo, pois pode marcar o início de uma saída da marginalidade. De excluídos a incluídos no laço social, pois a essas relações falta o reconhecimento do Estado. E todos nós sabemos da importância e interferência, real e simbólica, do Estado como um Grande-Pai, que autoriza, possibilita e facilita esta ou aquela relação. É assim com as relaçōes matrimoniais, e a partir de 1988 especialmente, com as rela- ções concubinárias, quando a Constituição em seu art. 226, reconheceu expressamente as uniões estáveis heterossexuais como entidade familiar.

Se nós profissionais do Direito, encontramos dificuldade para assuntos da sexualidade mais convencional, muito mais encontraremos para as não-convencionais, como a homossexualidade. Mas é uma questão que começa a se abrir. A polêmica é grande, as resistências são muitas, mas discuti-la jả será uma avanço. Pouquíssimos juristas escreveram sobre o assunto, e até evitam tocar nele. Talvez esse medo advenha da dificuldade com a própria sexualidade.

Dentre os raros, destaque-se o cientista do Direito, João Baptista Villela que, à frente de nosso tempo, apresenta-nos um texto longe do moralismo impeditivo de tratar o assunto profundamente. Assim, eticamente, escreveu:

No ambiente dessacralizado e pluralista das sociedades ocidentais contemnorâneas, sca inaceitáve! cestahele. cimento de restrições de direito em razão de preferências ou inclinações eróticas. Se a isso se ajuntar a circunstância de que o casamento deixou de ser um instituto preordenado à reprodução, para se constituir essencialmente em espaço de companheirismo e de camaradagem, era natural que se definisse a demanda pelo reconhecimento legal da uniâo entre parceiros do mesmo sexo. Afinal, podese dizer, retomando um feliz achado de Alice Rossi, que o sexo recreativo se impôs sobre o reprodutivo. Ainda que não

8. Noticia divulgada pela agência de noticias Agence France Press - AFP em 11/895. 
fosse assim, a procriação já não se dá exclusivamente na intimidade das alcovas. Dessacralizou-se ela própria, na medida em que se deixou controlar em laboratórios. Também aqui manifestou-se uma cesura fundamental: sexo e reproduçāo. Possível um sem a outra e vice-versa, os esquemas tradicionais tinham de ser repensados. Por fim, para favorecer a pretensão do casamento homossexual intervém a adoção, que imitando a natureza, segundo a velha parêmia, também a substitui. Se o que se pede para o bom desenvolvimento da criança, pode-se argumentar, é uma base convivencialestável, por que não reconhecê-la na união proposta para toda a vida entre duas pessoas de mesmo sexo? Que efeitos terá, contudo, sobre a criança o ambiente doméstico homossexual, quando é certo que as relaçōes sociais mais amplas em que ela se deverá inserir estão predominantemente marcadas pelo amor heterossexual? Uma educação para o exercício pleno da liberdade, se de algum modo for possível, haveria de assegurar escolhas autônomas também no domínio da sexualidade, de tal forma que a definição de cada um não resultasse de pressoes ou condicionamento, inclusive os ambientais. Esta ponderação, por si mesma, tanto fala contra os casamentos homossexuais, como fala a favor deles. Não pode, contudo, parece-me, deixar de ser tomada em conta para uma consistente avaliação do problema.

Por muito complexa que se apresente a questão, absolutamente nova tampouco é. Segundo relata Erle, a possibilidade do casamento entre pessoas do mesmo sexo já tinha sido considerada pelo jusnaturalista Johnann Wolfgang
Textor, um remoto ancestral de Goethe e que viveu entre 1638 e $1701 .^{9}$

Poucos projetos de lei, na história do Brasil, foram tão comentados e discutidos como o da parceria de pessoas do mesmo sexo. É o significado de que ele realmente interessa a todos os cidadãos. É que assuntos da sexualidade, muitas vezes tabu, despertam mesmo muita inquietação. Mas devemos nos perguntar: em quê e por quê este projeto afronta, ou incomoda tanto? Certamente está remexendo com os fantas. mas da sexualidade de cada um.

No meio legislativo, falou-se que aqueles que votassem a favor do Projeto Marta Suplicy, estariam legislando em causa própria. No meio religioso, invocaram o pecado e o fogo do inferno para os parlamentares e seguidores dessa idéia. Há tam. bém os defensores da ofensa à moralidade pública. Outros ainda, chegam a afirmar que seria um incentivo ao homossexualismo, pois os filhos de homossexuais seriam homossexuais, esquecendo-se de que se seguíssemos essa lógica, não haveriam homossexuais, pois os filhos de heterossexuais seriam necessariamente heterossexuais. No campo jurídico, a invocação é de inconstitucionalidade do pretenso texto normativo. Sabemos todos, entretanto, que a lógica jurídica é construída inclusive com elementos da subjetividade que, por sua vez, são determinados pelos valores morais de cada um. Por isso encontramos sempre, no Direito, posições contra e a favor de determinado, assunto. Mas esses posicionamentos são pré-determinados e determinados pela posição ética do sujeito

9. VILLELA, Joăo Baptista. As novas relaçōes da família. In: Anais da XV Conferência Nacional da $O A B$ em Foz do Iguaçu. Sã̃o Paulo: JBA Comuricaçōes, 1995. p. 642-643. 
na vida. No caso específico das relações homossexuais, interessa ao Direito por que das relaçōes de afeto decorrem conseqüências patrimoniais.

\subsection{0 conteúdo do projeto de parceria civil}

O projeto de parceria civil registrada entre pessoas do mesmo sexo propõe, basicamente:

a. Direito à herança e sucessão.

b. Benefícios previdenciários.

c. Declaração conjunta no IR e para aquisição de imóveis.

d. Direito à nacionalidade, no caso de estrangeiros que tenham como parceiros cidadã ou cidadão brasileiro.

Não propõe:

a. Dar status de casamento ou constituição de família. parceiro.

b. Alteração do sobrenome do

c. Mudança de estado civil.

d. Adoção, tutela e guarda conjunta de crianças.

Pelo texto do Projeto de Lei $n^{2} 1151$, em trâmite na Câmara dos Deputados, desde 1995 , constata-se que não se trata do registro de qualquer relação homossexual. A idéia é dar proteção e segurança às relações estáveis e monogâmicas, pois afinal, daí decorrem mesmo conseqüências jurídicas.

\section{Concluindo: Ética do Direito}

A discussão sobre as uniões de pessoas do mesmo sexo não pode significar fazer apologia da homo ou da heterossexualidade. Nem mesmo fazer uma política identitária, ou de minorias, pois essas divergem em suas premissas e argumentos que fundam suas posiçôes. Interessa-nos, enquanto profissionais do Direito, pensar e repensar melhor a liberdade dos sujeitos acima dos conceitos estigmatizantes $\mathrm{e}$ moralizantes que servem de instrumento de expropriação da cidadania. Interessa também ao Direito, pois das relações de afeto podem decorrer conseqüências patrimoniais; a ordenação jurídica para estar mais próxima do ideal de justiça e afinal cumprir sua função básica, deve estar voltada, antes das regras morais e estigmatizantes, para a libertaçāo dos sujeitos para que se cumpra a ÉTICA DO DIREITO.

\section{Bibliografia}

FACHIN, Luiz Edson. Aspectos jurídicos da uniāo de pessoas do mesmo sexo. In: RT, n. 732, out. 1996.

FREIRE, Jurandir. Entrevista. Jornal do Psicólogo, Belo Horizonte, $\mathrm{n}^{\mathrm{e}}$ 51, 1995.

FREUD, Sigmund. Totem e Tabu. In: Obras Psicológicas Completas. Trad. Orizon Carneiro. Rio de Janeiro: Imago, 1974. v. XII.

Notícia divulgada pela agência de notícias Agence France Press - AFP em 11/8/95.

O Melhor de Caetano Veloso - Sem Lenço sem documento. Local: Polygram, 1989.1 CD.

PEREIRA, Caio Mário da Silva. Revista do Instituto dos Advogados de Minas Gerais, Belo Horizonte, n. 1, 1995.

STRAUSS, Claude Levi. Estruturas elementares do parentesco. Trad. Mariano Ferreira. Petrópolis: Vo. zсз, 1982.

VILLELA, João Baptista. As novas relações da família. In: Anais da XV Conferência Nacional da $O A B$ em Foz do Iguaçu. São Paulo: JBA Comunicações, 1995.

VINDELOV, Vibeke. Family law in Denmark. In: Family, law and social policy - OÑATI. Valério Pocar and Paola Ronfani, 1991. 